\title{
Does Abortion Harm the Fetus?
}

\author{
Karl Ekendahl (D) and Jens Johansson* \\ Department of Philosophy, Uppsala University, Uppsala, Sweden \\ ${ }^{\star}$ Corresponding author. Email: jens.johansson@filosofi.uu.se
}

\begin{abstract}
A central claim in abortion ethics is what might be called the Harm Claim - the claim that abortion harms the fetus. In this article, we put forward a simple and straightforward reason to reject the Harm Claim. Rather than invoking controversial assumptions about personal identity, or some nonstandard account of harm, as many other critics of the Harm Claim have done, we suggest that the aborted fetus cannot be harmed for the simple reason that it does not occupy any well-being level.
\end{abstract}

\section{Introduction}

A central claim in abortion ethics is what we might call the Harm Claim - the claim that abortion harms the fetus.

It is plausible to think that the moral status of abortion depends substantially on whether the Harm Claim is true. In particular, since an action's harmfulness apparently counts morally against it, the Harm Claim can be used to argue for the moral impermissibility of abortion (see, e.g., Lee 2010: 34-35; Marquis 2004, 2005, 2008, 2011, 2013; Pruss 2011). Moreover, those who criticize the Harm Claim can use their criticism not only to respond to such anti-abortion arguments, but also to argue more directly for the thesis that abortion is morally permissible. After all, a natural view is that if abortion is harmless, then it does not require any special justification.

Our focus, however, will not be on the moral issue, but on the Harm Claim itself. We shall propose a simple and straightforward reason to reject the Harm Claim. Rather than invoking controversial assumptions about personal identity, or some nonstandard account of harm, as many other critics of the Harm Claim have done, we shall suggest that the aborted fetus cannot be harmed for the simple reason that it does not occupy any well-being level. This strategy for rejecting the Harm Claim has been previously neglected, and our main aim in this article is simply to draw attention to it and some of its advantages. Determining whether the strategy should, in the end, be wholeheartedly embraced requires further discussion (see section VII).

A clarification: what we will be concerned with, although this restriction will be largely left implicit, are abortions that are not unusually late - not performed after, say, week 20. Abortions that are unusually late give rise to special questions, at least on the approach that we shall propose. Those cases are important, too, but will not be discussed here.

(C) The Author(s), 2021. Published by Cambridge University Press. This is an Open Access article, distributed under the terms of the Creative Commons Attribution licence (http://creativecommons.org/licenses/by/4.0/), which permits unrestricted re-use, distribution and reproduction, provided the original article is properly cited. 


\section{The Harm Claim and the counterfactual comparative account}

It will be instructive to begin by considering the most popular and widely discussed view in the general debate on the nature of harm. This view is usually called the counterfactual comparative account:

The counterfactual comparative account. An event (e.g., an action) harms an individual if and only if, and to the extent that, the individual would have been on balance better off - that is, her lifetime well-being level would have been higher if it had not taken place. ${ }^{1}$

One prominent way of arguing for the Harm Claim - and one to which critics of the Harm Claim have been especially eager to respond - is to appeal to something like the counterfactual comparative account. For example, Don Marquis writes:

Killing someone harms her by making her life shorter, and therefore (typically) worse, than it otherwise would have been. Therefore, because killing someone makes her worse off, killing her harms her. (Marquis 2011: 4)

Similarly, Marquis claims that on his view,

premature death is a very serious harm and, like all harms, is understood as making an individual worse off than she otherwise would have been. (Marquis 2004: 56)

These remarks, Marquis contends, apply to abortion no less than to other kinds of killing. According to him, the aborted fetus would have gone on to have a valuable "future like ours" if it had not been aborted and would therefore have been overall better off than it actually is. Hence, abortion harms the fetus. ${ }^{2}$

It might thus seem that the counterfactual comparative account provides a straightforward reason to accept the Harm Claim. ${ }^{3}$ Importantly, however, the reason to deny the Harm Claim that we shall present is also a direct reason to deny that abortion

\footnotetext{
${ }^{1}$ For defenses of the counterfactual comparative account and closely related views, see, e.g., Bradley (2009), Feit (2015), (2016), Hanna (2016), Klocksiem (2012), and Timmerman (2019).

${ }^{2}$ E.g., Marquis (2004, 2005, 2008, 2011, 2013). Of course, Marquis's claim that abortion deprives the fetus of a valuable "future like ours" (a phrase made famous in Marquis 1989) can be used in various different ways in abortion ethics. Again, as we understand Marquis, his own view is that abortion makes the fetus overall worse off than it would have otherwise been (and thereby harms it) because it deprives the fetus of a valuable future like ours (see, e.g., Marquis 2011: 4, 11). Another possible view, which we shall consider briefly in section VII, is that an event can deprive an individual of a valuable future like ours without making her overall worse off, and that (contrary to the counterfactual comparative account) depriving her of such a future is sufficient for harming her. Yet another possible view is that an action's depriving an individual of a valuable future like ours may or may not be sufficient for harming her, but is sufficient for there to be a moral reason against it. As our focus is on the Harm Claim, we shall not discuss the latter view.

${ }^{3}$ Because some individuals would not have been well off even if they had been allowed to live, advocates of this strategy cannot say that every abortion harms the fetus (cf. the "typically" qualification in the above quote from Marquis 2011). They will thus want to restrict the scope of the Harm Claim to more typical cases. This complication does not affect our own approach (sections IV-V), which applies both to cases where the fetus would have been well off if it had been allowed to live and to cases where it would not.
} 
satisfies the condition in the counterfactual comparative account. If our proposal is right, then, the counterfactual comparative account does not support the Harm Claim, but its denial.

\section{Two other strategies}

It will also be instructive, especially in virtue of bringing out the advantages of our own strategy, to briefly consider two other strategies for rejecting the Harm Claim. Both of these strategies appeal, in different ways, to the fetus's lack of psychological connections to the individual who, in the absence of abortion, will receive various goods in the future.

The first strategy is to argue that abortion cannot harm the fetus since no future goods would have awaited the fetus even if it had not been aborted (see, e.g., Brill 2003; McInerney 1990; McMahan 2002; Reitan 2016). This strategy is motivated by the view that we have never been fetuses, but instead started to exist at a later point in particular, when a sufficiently rich psychology emerged. Clearly, in order for it to be true that a fetus would have received future goods if it had not been aborted, it needs to be true that the fetus would have been identical to some future recipient of goods. Thus, if we have never been fetuses, proponents of this strategy argue, then abortion would not have deprived us of future goods.

This strategy is compatible with the counterfactual comparative account. But of course, it involves rejection of animalism, the view that we are human animals. ${ }^{4}$ Since the animal with which you are associated has been a fetus, it follows from animalism that you have been a fetus. Aborting the fetus would thus have prevented it from receiving the goods that you actually receive. While proponents of the present strategy might not regard rejection of animalism as a serious cost, many others do - after all, animalism is one of the major views of personal identity. ${ }^{5}$ Surely it is at least interesting to see if there is a plausible strategy for rejecting the Harm Claim that is neutral with respect to animalism.

The second strategy for rejecting the Harm Claim appeals to an account of the harm of killing and death that takes psychological connections more seriously than the counterfactual comparative account (e.g., DeGrazia 2005; McMahan 2002). The general idea is that even if a killing or death prevents the individual from receiving various future goods and thereby makes her overall worse off than she would have otherwise been, it harms her only if she would have been, at the future times at which she would have received those goods, psychologically connected to herself as she is before death. Now, the aborted fetus never has any psychology at all (recall that we are not here concerned with late fetuses). Hence, abortion does not harm it.

Unlike the first strategy, this strategy does not leave the denial of the Harm Claim hostage to any disputed claims about personal identity - in particular, it is compatible with animalism. However, the view of harm to which this strategy appeals is a rather radical one, which also has few advocates in the general debate on the nature of

\footnotetext{
${ }^{4}$ Even if rejecting animalism is necessary for this strategy to work, it is not clear that it is sufficient. In particular, even if you have never been a fetus, it remains the case that the animal with which you are associated has been a fetus. And isn't it happy whenever you are happy? If it is, abortion would have deprived it of this happiness. Thus, contrary to what Marquis himself $(2002,2013)$, along with many others, apparently thinks, it is not clear that his argument presupposes animalism. See further Johansson (2019).

${ }^{5}$ For a thorough defense of animalism, see Olson (1997). For specifically abortion-related defenses of animalism, see, e.g., Kaczor (2011), Lee (1997, 2010), Marquis (2013), and Pruss (2011).
} 
harm. In particular, it is hard to swallow that an event can be entirely harmless even if it makes the individual much worse off than she would have otherwise been and fails to make her well off. While we do not rule out the possibility that this nonstandard view of harm is in the end defensible, surely it is interesting to see if we can deny the Harm Claim without invoking it.

Unlike the two strategies just considered, our own strategy, to which we now turn, is compatible with the conjunction of animalism and the counterfactual comparative account. It is also compatible with both animalism and the counterfactual comparative account being false, and with exactly one of them being true.

\section{The Well-Being Requirement}

Our strategy appeals to an attractive and widely endorsed principle that states a necessary condition for harming (this section), and to a specific reason to doubt that this condition is satisfied in the case of abortion (next section).

Here is the principle:

The Well-Being Requirement. In order for an event to harm an individual, the individual has to occupy a lifetime well-being level.

Two initial remarks are in order. First, we take it that someone has a lifetime well-being level (that is, is on balance well off to some degree) just in case she has, at some time or another, a temporal well-being level (that is, is well off to some degree at some particular time). How the individual's lifetime well-being level is more specifically related to her various particular temporal well-being levels will not be relevant here. Second, the Well-Being Requirement should not be conflated with the claim that an event harms someone only if she has a temporal well-being level at the time of the occurrence of the event. The latter claim is highly questionable. Arguably, for instance, you did not occupy any temporal well-being level at all several years before your birth. Yet an event that happened then can clearly harm you - for instance, by causing you to be in pain ten years from now. The Well-Being Requirement is fully compatible with this judgment, since you obviously have a lifetime well-being level.

The Well-Being Requirement is an implication of all main views in the general debate on the nature of harm. To begin with, if the counterfactual comparative account is true, then in order for an event to harm an individual, it is not sufficient that, for instance, the individual does not actually occupy a positive well-being level but would have done so if it were not for the event. What is required is for the individual to have a lower well-being level than she would have had if the event had not occurred. And in order for her to have a lower well-being level than she would have otherwise had, she must have a well-being level. Hence, the counterfactual comparative account implies the Well-Being Requirement.

Similarly, consider standard versions of the main competitor to the counterfactual comparative account, the causal account of harm (see further Carlson, Johansson, and Risberg 2021a). On one such version, known as the "temporal" view, an event harms someone if and only if it causes her to have a lower temporal well-being level after the event rather than before it (e.g., Foddy 2014). On another, an event harms someone if and only if it causes her negative well-being (e.g., Smuts 2012). On yet another, an event harms someone if and only if it causes the obtaining of a state of affairs that satisfies various conditions, including that she would have had a higher well- 
being level if that state of affairs had not obtained (e.g., Gardner 2015). The Well-Being Requirement evidently follows from each of these views. ${ }^{6}$

Not only is the Well-Being Requirement a consequence of the main theories in the general debate on the nature of harm; various objections and moves in that debate also accord with it. Consider for example two important objections to the counterfactual comparative account (for further discussion, see, e.g., Bradley 2012; Carlson and Johansson 2018; Feit 2015, 2016; Johansson 2021; Johansson and Risberg 2019). The first one concerns preemption. Suppose someone punches you in the face, but would have otherwise killed you. Then his actual action seems to harm you, contrary to the counterfactual comparative account. The second objection concerns creation. Suppose we create someone who is bound to be very unhappy, and that if we had not created her, she would have never existed. Again, it seems that our action harms her. Plausibly, though, she would not have had any well-being level at all (and thus would not have been better off) if she had never existed. No matter how fatal these problems may be for the counterfactual comparative account, however, they do not threaten the Well-Being Requirement. For in both these cases - the preemption case and the creation case - the victim does have a lifetime well-being level.

\section{Does the aborted fetus have a well-being level?}

A crucial question, then, is whether the aborted fetus has a lifetime well-being level. It seems clear that the aborted fetus never occupies a positive or negative well-being level. Not only is this the intuitive thing to say, it is also entailed by all standard substantive views of well-being, such as hedonism or desire satisfactionism. (The aborted fetus never feels pleasure or pain and has no desires.) Of course, this does not by itself rule out the possibility that the fetus occupies a neutral well-being level - a well-being level of zero. However, there is a good (though by no means decisive) reason for denying that the fetus has even a neutral well-being level. The reason can be found in the well-being literature, but has to our knowledge not yet been applied to the issue of abortion (see, e.g., Carlson and Johansson 2018; Herstein 2013; Johansson 2021; Luper 2007, 2009: 132-33).

Consider, for a moment, an ordinary computer instead of a fetus, and some scales other than the well-being scale - such as those of wealth and moral virtue. Clearly, the computer has no positive or negative wealth. Does it have zero wealth, making it poorer than most people and richer than some (those whose debts exceed their assets)? While some would be prepared to accept that it does, surely that is not the most intuitive thing to say. A more natural view is that the computer does not occupy any financial level at all. ${ }^{7}$ World poverty is not increased by the coming into being of a standard Dell laptop. Similarly, the computer is neither virtuous nor vicious; it occupies neither a positive nor a negative level on the virtue scale. Does it occupy a zero level, making it more virtuous than a bad person and less virtuous than a good person? Again, that is a

\footnotetext{
${ }^{6}$ It also follows from the view defended in Johansson and Risberg (forthcoming), and from all views considered in Carlson, Johansson, and Risberg (2021b).

${ }^{7}$ Some might want to say that sentences like, "The computer occupies some financial level" are meaningless (and similarly with other relevant examples below). If so, sentences like, "The computer occupies no financial level" are also meaningless. While the meaninglessness view is inconsistent with the letter of our strategy, our various claims could easily be reformulated to accommodate it. Thanks to Naomi Korem and an anonymous referee for helpful discussion.
} 
possible position to take, but not the most intuitive one. On a more natural view, the computer occupies no level at all on the virtue scale.

If the computer indeed occupies no level on the wealth scale, or the virtue scale, what is the explanation of this? It cannot merely be that the computer does not actually occupy any positive or negative level on the wealth scale, or the virtue scale. After all, that condition can be satisfied also by ordinary humans who occupy a zero level (rather than no level) on the wealth scale, or the virtue scale. Plausibly, the explanation is rather that the computer, unlike such humans, has no capacity for being wealthy or unwealthy, or virtuous or vicious. While it is difficult to analyze the notion of a capacity, surely it has at least largely to do with the object's internal structure. The computer's internal structure, unlike that of an ordinary human, is not even somewhat fit to produce the mental and social states relevant to positive and negative wealth, and to virtue and vice (whatever those states exactly are). Indeed, it seems to us most intuitive to say that even if it were to turn out, surprisingly, that an ordinary computer in the natural course of events will eventually acquire a capacity for positive and negative wealth, and virtue and vice - perhaps by acquiring certain mental and social properties it still would not occupy any level on the wealth scale, or virtue scale, until it actually got that capacity. Even in such a scenario, no matter how wealthy or virtuous the computer will eventually become, it will not become richer or morally better than it currently is. Currently, it is not even in the competition.

No doubt all this could be questioned, and particularly by someone with other intuitions. What we suggest is merely that the above is sufficiently plausible to be able to constitute the basis of a sensible and interesting strategy for denying the Harm Claim.

Return now to well-being. An ordinary computer apparently has no capacity for positive or negative well-being - a capacity for receiving positive and negative well-being components. Surely, moreover, if its lack of a capacity for positive or negative wealth, or virtue or vice, explains its occupying no level (rather than a zero level) on the wealth scale, or virtue scale, then its lack of a capacity to have a positive or negative well-being level implies that, and explains why, it occupies no level (rather than a zero level) on the well-being scale. The computer fails to be better or worse off than any of us since it is not capable of having whatever constitutes positive or negative well-being. And again, even if it were to eventually acquire this capacity, this would not mean that it currently has a well-being level of zero - and if it never acquires such a capacity, it has no lifetime well-being level at all.

Now, a fetus, too, plausibly has no capacity for having positive or negative wellbeing. On the most popular substantive theories of well-being, at least, mental properties are needed for positive or negative well-being. On hedonism, for example, positive well-being consists in pleasure, and negative well-being in pain. On desire satisfactionism, positive and negative well-being consists in the satisfaction and frustration, respectively, of desires. And pluralists about well-being, too, usually include in their lists only items that require mental features: knowledge, rational activity, friendship, etc. ${ }^{8}$ Indeed, these items require more in terms of mental sophistication than do pleasure, pain, and desire. Crucially, the fetus - at least, the relatively early fetus (see section I) - is not capable of having mental features, and hence not capable of having a positive or negative well-being level. It probably will acquire such a capacity if it is not aborted; but if it is aborted, it never has it. So, while an aborted fetus would have had a well-being level if it

${ }^{8}$ In section VII, we briefly consider a pluralist view that does not have this feature. 
had not been aborted, it never actually has it. Consequently, abortion and fetuses do not satisfy the necessary condition for harming stated in the Well-Being Requirement.

It is important to note that our point is not merely that the fetus has no temporal well-being level at the time of abortion. As we stressed in section IV, an event can harm someone even if she has no temporal well-being level at the time of the occurrence of the event. Indeed, lots of things that happen to a fetus that will not be aborted can harm it - say, by causing it to be in pain after birth, or by causing it to die prematurely at the age of fifty. After all, such a fetus has many temporal well-being levels later in life; as a result, it also has a lifetime well-being level. In the case of a fetus that does get aborted, however, things are different. If our proposal is right, the aborted fetus never has any temporal well-being level, and therefore has no lifetime well-being level. Given the Well-Being Requirement, then, nothing, including abortion, harms it.

Some writers, especially in the Thomistic tradition, insist that the fetus, even from the very beginning of its existence, in one important sense actually does have a capacity for mental states - and indeed for knowledge, rational activity, friendship, etc. (e.g., Beckwith 2007: 142; Finnis 2013; Lee 2004, 2010: 6, 52; Lee and George 2005; cf. Kaczor 2011: 30). ${ }^{9}$ According to these theorists, the fetus has already from the start a "radical" or "root" capacity for such features, roughly in the sense of having a potential for them: the fetus has the right sort of nature to eventually acquire these features, so long as nothing prevents it from doing so. This is much in the same way that an acorn has a root capacity to grow branches and leaves (cf. Beckwith 2013: 342). Although this view raises large issues that we cannot do justice to in this article, we are inclined to say that it does not, even if correct, undermine our strategy. For while we find somewhat misleading the broad use of the term 'capacity' involved in this view, it seems to us that we can accept it without jeopardizing the substance of our proposal. For the important thing is, of course, whether having a mere root capacity for the relevant features is sufficient for occupying some level on the pertinent scale. It seems to us that it is not. As indicated earlier, even if an ordinary computer were to turn out to have a root capacity for positive and negative wealth, or virtue and vice, intuitively it would still need a more substantially developed capacity in order to occupy any level on the wealth scale, or virtue scale. (Presumably, there will be borderline cases between having a mere root capacity and having a sufficiently developed capacity - but the computer seems to be a clear instance of the former.) Similarly, an early fetus apparently has a root capacity for positive and negative wealth, and for virtue and vice. Nevertheless, it is still plausibly not richer than some of us and poorer than most, or more virtuous than a bad person and less virtuous than a good person. If this is right, surely the same holds for well-being.

Ben Bradley is skeptical of the capacity approach to well-being levels on which our strategy relies. To support his doubts, he supposes for the sake of argument that hedonism is true, and considers the lives of two people: Marsha, who never acquires the capacity to experience pleasure or pain, and Greg, who has that capacity, but never actually experiences any pleasure or pain. If having a well-being level of zero requires having the capacity for receiving positive or negative well-being components, then there is a significant difference between Marsha and Greg: while Greg has a permanent well-being level of zero, Marsha has no well-being level at all. In Bradley's view, however, this "just seems wrong” (Bradley 2009: 103). A more plausible judgment, he suggests, is that both Marsha and Greg occupy a well-being level of zero.

\footnotetext{
${ }^{9}$ Thanks to an anonymous referee for urging us to address this view.
} 
We do not share Bradley's intuitions about the case of Marsha and Greg. That is, we do not find it intuitively wrong to say that Marsha has no well-being level, or that there is a significant difference between Marsha and Greg with respect to well-being. More importantly, however, our strategy does not rely on any intuitions about the well-being levels (or lack thereof) of people like Marsha - or, for that matter, any human being. Indeed, our strategy does not even rely on any intuitions about well-being levels. In motivating our strategy, we have suggested that that there is a common and plausible explanation of why a computer, for instance, occupies no level on certain other scales, such as those of wealth and virtue - an explanation that, when applied to well-being and fetuses, yields the result that fetuses occupy no well-being level. Unless Bradley's intuition that Marsha has a well-being level is very strong, then, it threatens neither our support for the capacity approach nor the capacity approach itself.

According to current scientific consensus, a fetus acquires the (nonroot) capacity for mental features around week 20. It is worth noting that our approach thus does not rule out the possibility that the Harm Claim is true for fetuses that are aborted later than that. But as pointed out in section I, in this article we are not concerned with such unusually late abortions. The great majority of abortions are performed long before week 20 .

In this context, it is also worth noting that our proposal has the attractive feature of ruling out the possibility that abortion harms the early fetus, without ruling out the possibility that infanticide harms the infant. Again, our strategy does not rule out the possibility that late fetuses may be harmed by abortion, since, unlike early fetuses, late fetuses may well have a well-being level. Unsurprisingly, the same goes for infants. Moreover, this way of ruling out the harmfulness of early abortion without ruling out the harmfulness of infanticide does not appeal to the fact that, unlike early fetuses, infants are typically conscious. Thus, our strategy is not vulnerable to the criticism, recently raised by David Hershenov and Rose Hershenov among others, that the presence or absence of consciousness is not in itself relevant to whether an individual can be harmed (Hershenov and Hershenov 2017: 393-95; cf. Kaczor 2011: ch. 3). What is relevant, on our suggestion, is whether the individual meets the condition stated in the Well-Being Requirement. Similarly, although some coma patients may be no more capable of receiving well-being components than are fetuses, our proposal does not imply that such patients cannot be harmed by death. ${ }^{10}$ Since, typically, a comatose individual has had the relevant capacities, and hence a temporal well-being level, at many times prior to her becoming comatose, she has a lifetime well-being level, and so meets the relevant condition in the Well-Being Requirement. ${ }^{11}$

\section{Two nearby suggestions}

Our strategy has some similarities with suggestions from Bradley and Nathan Nobis and Kristina Grob. Let us briefly consider their proposals in turn and point out how they differ from ours.

\footnotetext{
${ }^{10}$ This worry, too, can be found in Hershenov and Hershenov (2017: 402). See also Beckwith (2011) and Kaczor (2011: sect. 2.4).

${ }^{11}$ Some writers in the debate on the ethics of abortion (e.g., Beckwith 2007: 135, 137) have wondered how the moral status of, say, killing a comatose individual could be affected by whether the individual has had certain capacities in the past. Our strategy might provide an answer to this question. Plausibly, an action's moral status can be affected by whether the action harms an individual. On our strategy, killing the comatose individual harms her only if she has a lifetime well-being level - something that, in turn, requires her to have the capacity for positive or negative well-being at some point (e.g., in the past).
} 
Bradley has recently suggested an account of the badness of an event for an individual, which, when applied to abortion, might seem similar to our suggestion (Bradley 2019). According to Bradley's account, the badness of an event is not determined solely by whether, and to what extent, an individual would have been better off if the event had not occurred; it is also partly determined by the degree to which the individual is a welfare subject: the lower the individual's degree of being a welfare subject, the larger the discount on the badness of the loss of well-being. Because Bradley apparently takes the degree to which an individual is a welfare subject to correspond to the degree to which she is capable of receiving positive and negative well-being components, his account, similarly to our suggestion, rules out the possibility that abortion is bad for the fetus on the grounds that the fetus lacks such a capacity. Even so, and even disregarding (as we shall do here) potential discrepancies between badness and harm, our strategy for rejecting the Harm Claim is importantly different from the one provided by Bradley's account.

While our strategy appeals to the fact that fetuses lack well-being levels, the Bradley strategy does not - indeed, as his judgment in the case of Marsha and Greg (section V) indicates, Bradley himself seems not to deny that fetuses and other beings who lack mental capacities have well-being levels like the rest of us. ${ }^{12}$ Instead, it appeals to a very specific view of harm, which is incompatible with the counterfactual comparative account. Our strategy, by contrast, relies on only the Well-Being Requirement, which, again, is entailed by every standard view of harm (including the counterfactual comparative account). Moreover, just like proponents of the second strategy for denying the Harm Claim considered in section III, adherents of the Bradley strategy are committed to denying the natural idea that any event that makes an individual much worse off than she would have otherwise been, and does not make her well off, is harmful to the individual. On Bradley's view, such an event harms the individual only if she is also a welfare subject to a non-zero degree. By contrast, our strategy allows its adherents to accept that if an event makes someone much worse off than she would otherwise have been and does not make her well off, then the event harms her. ${ }^{13}$

Nobis and Grob present their approach as follows:

If a being is and has always been completely unconscious, that being cannot be harmed, which requires a 'turn for the worse' for that being. But there is no 'for that being' for early fetuses yet, so things can't get worse for them. So killing them doesn't harm them or make them worse off, compared to how they were, since they never 'were' in a conscious way. (Nobis and Grob 2019: 48)

While this, too, is reminiscent of our suggestion, there are at least two important differences between our strategy and Nobis and Grob's. First, as the quote indicates, Nobis and Grob apparently suggest that, in order for an event to harm an individual, it has to make her worse off than she was before the event took place. In other words, they appeal to a temporal account of harm (see section IV). We, by contrast, do not: while the temporal account presupposes the Well-Being Requirement, the reverse obviously does not hold. Because such a temporal account of harm is vulnerable to a host of

\footnotetext{
${ }^{12}$ Bradley (2009: ch. 3) also argues that an individual occupies a well-being level of zero when she is dead - a view that is hard to combine with the claim that a fetus does not have a well-being level.

${ }^{13}$ Bradley's account also rests on the assumption that being a welfare subject comes in degrees, whereas our proposal is silent on this matter.
} 
serious problems that do not threaten the Well-Being Requirement, this is an advantage of our strategy over Nobis and Grob's. ${ }^{14}$ Second, Nobis and Grob say that no being that is always unconscious can be harmed. By contrast, we are only committed to saying that insofar as consciousness is required for receiving well-being components, no being that lacks the capacity to have consciousness has a well-being level.

\section{Concluding remarks}

We shall close by mentioning five different lines of response available to our critics.

First, a critic might want to reject the idea that some things occupy no level at all on certain scales. For instance, the critic might insist that an ordinary computer does occupy a level - most likely, a zero level - on the scales of wealth, virtue, and wellbeing. ${ }^{15}$ Presumably, this would be because not occupying a positive or negative level of some scale is, after all, sufficient for occupying a zero level on that scale. Appearances to the contrary, the critic might say, can be explained away.

Second, the critic might grant that many things occupy no level at all on certain scales, but deny that this is because they lack the capacity for occupying a positive or negative level on those scales. Some alternative explanation is preferable, the critic might suggest - and maybe that alternative explanation does not yield the result that a fetus lacks a well-being level.

Third, as we have pointed out, our strategy for rejecting the Harm Claim is compatible with standard substantive views of well-being: hedonism, desire satisfactionism, etc. However, the critic might want to appeal to some alternative view of well-being, on which positive and negative well-being does not require mental states. Naturally, not just any such view would do, even if correct. For instance, some might want to say that a human being who spends her entire and long life in a vegetative state occupies a negative well-being level - perhaps because of something to do with lack of dignity or personal relations. ${ }^{16}$ Surely any sensible version of such a view will have to deny that such factors are present in the case of the fetus. For instance, an early fetus is not lacking in dignity for lacking mental states. However, a suggestion that might be more adequate to our critics' needs is that, say, being healthy or being alive is a positive well-being component. ${ }^{17}$ If that is right, the fetus does occupy a well-being level, and so does, after all, meet the Well-Being Requirement. It should be noted, though, that on such a view a typical early fetus already has a positive temporal well-being level - a surprising, if not indefensible, claim.

Fourth, the critic might try to argue that even given hedonism and other standard accounts of well-being, even an early fetus does have a capacity for positive or negative well-being. The fetus actually has a capacity for pleasure and pain, for example. This strategy might, but need not, involve the claim that we are also wrong to suggest that an ordinary computer has no capacity for occupying a positive or negative level on

\footnotetext{
${ }^{14}$ The creation problem for the counterfactual comparative account (see section IV), for instance, is also a problem for the temporal account of harm. Unless the individual had a well-being level before she even existed, creating her cannot make her worse off than she was before. For further problems for the temporal account, see Carlson, Johansson, and Risberg (2021a).

${ }^{15}$ Feit (2016: 145) embraces this sort of claim with regard to the well-being scale. See further Carlson and Johansson (2018).

${ }^{16}$ Thanks to an anonymous referee for helpful discussion here.

${ }^{17}$ The appeal to being alive might seem to be a natural one to make for those who think, as many in the pro-life literature do, that human life is intrinsically valuable (e.g., Lee 2010: 157-58; cf. Marquis 2011: 16-19). It is not clear, however, what implications the latter view has for well-being in particular.
} 
the scales of wealth, virtue, and well-being. And the strategy might, but perhaps need not, involve saying that a mere "root" capacity for positive and negative well-being is after all (despite our remarks in section V) sufficient for occupying a well-being level.

Fifth, the critic might reject the Well-Being Requirement. While, as we have pointed out (section IV), the Well-Being Requirement is common ground for all standard views in the debate on the nature of harm, the critic might argue that these views are all wrong. Of course, the falsity of these views does not entail the falsity of the Well-Being Requirement. But the critic might want to defend some view about harm (which need not amount to a complete view of the nature of harm) that does entail the falsity of the Well-Being Requirement. The critic might, for instance, suggest that any event that causes an individual's death thereby harms her, whether or not she ever occupies any well-being level (see, e.g., Harman 2009: 139). This claim, in this unqualified form, would also entail the Harm Claim. On the other hand, the claim seems unreasonable in this unqualified form. In particular, it does not seem attractive to say that even an individual who not only never actually occupies any well-being level, but also would not have done so even if she had continued to live, can be harmed by being caused to die. A better approach for our critic to adopt might be to say that an action can harm someone by preventing her from occupying a positive well-being level, even if she never actually occupies any well-being level. ${ }^{18}$ This, too, seems to imply the Harm Claim. On the face of it, however, this approach also seems to yield the result that the following claim is true: if an ordinary computer never occupies any well-being level, but we could somehow cause it to occupy a positive one, then an action that prevents us from doing so harms the computer. This does not seem like an appealing implication. Those who defend the approach should try to find a way to block it, or to show that it is acceptable after all.

As pointed out in section I, our main aim in this article is to draw attention to a strategy for rejecting the Harm Claim that has been previously overlooked and has some noteworthy advantages. It is simple, it invokes no nonstandard view of harm or personal identity, and its individual components are natural and commonsensical. Whether our strategy should in the end be accepted can be settled only by further investigation. Showing the correctness of one or several of the five lines of response mentioned here (or some sixth line of response) might not be a hopeless task for our critics. But it does strike us as a difficult task - and in any case, it is a task that they need to undertake. ${ }^{19}$

Competing Interests. The authors declare there are no competing interests.

\section{References}

Beckwith, Francis J. 2007. Defending Life: A Moral and Legal Case Against Abortion Choice (Cambridge, MA: Cambridge University Press).

Beckwith, Francis J. 2011. The Human Being, a Person of Substance: A Response to Dean Stretton. In Persons, Moral Worth, and Embryos, ed. by Stephen Napier (Dordrecht: Springer), 67-83.

\footnotetext{
${ }^{18}$ Pruss (2011) claims that abortion harms the fetus by depriving it of a valuable continued life, and at least does not explicitly say anything that entails the Well-Being Requirement.

${ }^{19}$ Earlier versions of this article were presented at the University of Kansas (2018), the Personal Identity and Bioethics conference at the University Duisburg-Essen (2018), Filosofidagarna at Umeå University (2019), and Tel Aviv University (digital event, 2021). Thanks very much to everyone who participated (not least, Don Marquis at the Kansas session). For helpful written comments, we thank Susanne Burri, Naomi Korem, Dale Miller, Olle Risberg, and two anonymous referees for this journal. Jens Johansson's work on this article was supported by Grant 2018-01361 from Vetenskapsrådet. Karl Ekendahl's work was supported by Grant 2019-00511 from Vetenskapsrådet.
} 
Beckwith, Francis J. 2013. Potentials and Burdens: A Reply to Giubilini and Minerva. Journal of Medical Ethics 39: 341-44.

Bradley, Ben. 2009. Well-Being and Death (Oxford: Oxford University Press).

Bradley, Ben. 2012. Doing Away with Harm. Philosophy and Phenomenological Research 85: 390-412.

Bradley, Ben. 2019. A Gradualist View about the Badness of Death. In Saving People from the Harm of Death, ed. by Espen Gamlund and Carl Tollef Solberg (New York: Oxford University Press), 134-45.

Brill, H. Skott. 2003. The Future-Like-Ours Argument, Personal Identity, and the Twinning Dilemma. Social Theory and Practice 29: 419-30.

Carlson, Erik and Jens Johansson. 2018. Well-Being without Being? A Reply to Feit. Utilitas 30: 198-208.

Carlson, Erik, Jens Johansson, and Olle Risberg. 2021a. Causal Accounts of Harming. Pacific Philosophical Quarterly. Online first. DOI: 10.1111/papq.12390

Carlson, Erik, Jens Johansson, and Olle Risberg. 2021b. Well-Being Counterfactualist Accounts of Harm and Benefit. Australasian Journal of Philosophy 99: 164-74.

DeGrazia, David. 2005. Human Identity and Bioethics (Cambridge: Cambridge University Press).

Feit, Neil. 2015. Plural Harm. Philosophy and Phenomenological Research 90: 361-88.

Feit, Neil. 2016. Comparative Harm, Creation and Death. Utilitas 28: 136-63.

Finnis, John. 2013. Capacity, Harm and Experience in the Life of Persons as Equals. Journal of Medical Ethics 39: 281-83.

Foddy, Bennett. 2014. In Defense of a Temporal Account of Harm and Benefit. American Philosophical Quarterly 51: 155-65.

Gardner, Molly. 2015. A Harm-Based Solution to the Non-Identity Problem. Ergo: An Open Access Journal of Philosophy 2: 427-44.

Hanna, Nathan. 2016. Harm: Omission, Preemption, Freedom. Philosophy and Phenomenological Research 93: $251-73$.

Harman, Elizabeth. 2009. Harming as Causing Harm. In Harming Future Persons, ed. by Melinda A. Roberts and David T. Wasserman (Dordrecht: Springer), 137-54.

Hershenov, David B. and Rose J. Hershenov. 2017. If Abortion, then Infanticide. Theoretical Medicine and Bioethics 38: 287-409.

Herstein, Ori J. 2013. Why 'Nonexistent People' Do Not Have Zero Wellbeing but No Wellbeing at All. Journal of Applied Philosophy 30: 136-45.

Johansson, Jens. 2019. Deprivation and Identity. In Saving People from the Harm of Death, ed. by Espen Gamlund and Carl Tollef Solberg (New York: Oxford University Press), 163-74.

Johansson, Jens. 2021. Two Arguments for Epicureanism. In Exploring the Philosophy of Death and Dying, ed. by Michael Cholbi and Travis Timmerman (New York: Routledge), 70-77.

Johansson, Jens and Olle Risberg. 2019. The Preemption Problem. Philosophical Studies 176: 351-65.

Johansson, Jens and Olle Risberg (forthcoming). A Simple Analysis of Harm. Ergo: An Open Access Journal of Philosophy.

Kaczor, Christopher. 2011. The Ethics of Abortion: Women's Rights, Human Life, and the Question of Justice (New York: Routledge).

Klocksiem, Justin. 2012. A Defense of the Counterfactual Comparative Account of Harm. American Philosophical Quarterly 49: 285-300.

Lee, Patrick. 1997. Human Beings Are Animals. International Philosophical Quarterly 37: 291-303.

Lee, Patrick. 2004. The Pro-Life Argument from Substantial Identity: A Defence. Bioethics 18: $249-63$.

Lee, Patrick. 2010. Abortion and Unborn Human Life, 2nd edn (Washington, DC: The Catholic University of America Press).

Lee, Patrick and Robert P. George. 2005. The Wrong of Abortion. In Contemporary Debates in Applied Ethics, ed. by Andrew I. Cohen and Christopher Heath Wellman (New York: Blackwell Publishers), 13-26.

Luper, Steven. 2007. Mortal Harm. Philosophical Quarterly 57: 239-51.

Luper, Steven. 2009. The Philosophy of Death (Cambridge: Cambridge University Press).

McInerney, Peter K. 1990. Does a Fetus Already Have a Future-Like-Ours? Journal of Philosophy 87: 264-68.

McMahan, Jeff. 2002. The Ethics of Killing (Oxford and New York: Oxford University Press).

Marquis, Don. 1989. Why Abortion Is Immoral. The Journal of Philosophy 86: 183-202. 
Marquis, Don. 2002. Does Metaphysics Have Implications for the Morality of Abortion? Southwest Philosophy Review 18: 73-78.

Marquis, Don. 2004. Korcz's Objections to the Future-of-Value Argument. Journal of Social Philosophy 35 : 56-65.

Marquis, Don. 2005. Savulescu's Objections to the Future of Value Argument. Journal of Medical Ethics 31: 119-22.

Marquis, Don. 2008. Abortion and Human Nature. Journal of Medical Ethics 34: 422-26.

Marquis, Don. 2011. Why Abortion Is Seriously Wrong: Two Views. In Bioethics with Liberty and Justice: Themes in the Work of Joseph Boyle, ed. by Christopher Tollefsen (Dordrecht: Springer), 3-22.

Marquis, Don. 2013. Abortion and Death. In The Oxford Handbook of Philosophy of Death, ed. by Ben Bradley, Fred Feldman, and Jens Johansson (New York: Oxford University Press), 409-31.

Nobis, Nathan and Kristina Grob. 2019. Thinking Critically About Abortion: Why Most Abortions Aren't Wrong and Why All Abortions Should Be Legal (Atlanta, GA: Open Philosophy Press).

Olson, Eric T. 1997. The Human Animal: Personal Identity Without Psychology (New York: Oxford University Press).

Pruss, Alexander R. 2011. I Was Once a Fetus: That Is Why Abortion Is Wrong. In Persons, Moral Worth, and Embryos, ed. by Stephen Napier (Dordrecht: Springer), 19-42.

Reitan, Eric. 2016. Avoiding the Personhood Issue: Abortion, Identity, and Marquis's 'Future-Like-Ours' Argument. Bioethics 30: 272-81.

Smuts, Aaron. 2012. Less Good but Not Bad: In Defense of Epicureanism About Death. Pacific Philosophical Quarterly 93: 197-227.

Timmerman, Travis. 2019. A Dilemma for Epicureanism. Philosophical Studies 176: 241-57.

Cite this article: Ekendahl K, Johansson J (2022). Does Abortion Harm the Fetus? Utilitas 34, 154-166. https://doi.org/10.1017/S0953820821000406 